\title{
DIAGNÓSTICO DE ENFERMEDADES EN COLMENAS DE ABEJAS AFRICANIZADAS EN COSTA RICA: PREVALENCIA Y DISTRIBUCIÓN DE SETIEMBRE A NOVIEMBRE DEL 2007
}

\author{
Rafael A. Calderón ${ }^{1 / *}$, Luis A. Sánchez*
}

Palabras clave: Loque, Acariosis, Nosemiasis, Varroosis, abejas Africanizadas, prevalencia, muestreo nacional. Keywords: Foulbrood, Tracheal mites, Nosema disease, Varroosis, Africanized honey bees, prevalence, national sampling.

\section{RESUMEN}

Reportes sobre la prevalencia y distribución de enfermedades en abejas africanizadas en Costa Rica son escasos. Se han realizado algunos estudios para determinar su presencia, sin embargo la información no ha sido completa; por lo anterior, el objetivo de este estudio fue determinar la prevalencia de las principales enfermedades que afectan tanto a la cría como a las abejas adultas en Costa Rica. Se realizó un muestreo nacional de abejas adultas y panales, de setiembre a noviembre del 2007. La mayoría de muestras se recolectaron en las provincias de San José, Guanacaste y Alajuela. En total se analizaron mediante técnicas de laboratorio 161 muestras de panal y 163 de abejas, pertenecientes a 96 apicultores. Se determinó una alta prevalencia de Loque europeo $(54,7 \%)$, Nosemiasis $(67,5 \%)$ y Varroosis (cría $=37,9 \%$, abejas $=40,5 \%)$; mientras que únicamente un $1,8 \%$ y un $4,4 \%$ de las muestras fue positiva para Acariosis y Cría de Tiza, respectivamente. Todas las muestras resultaron negativas a Loque americano. La mayor prevalencia de Loque europeo se presentó en octubre; mientras que en setiembre se determinó la menor cantidad. Un 60,0\% (n=61) de las

1 Autor para correspondencia. Correo electrónico: rcalder@una.ac.cr
ABSTRACT

Diagnosis of bee diseases in africanized honey bees in Costa Rica: prevalence and distribution from September to November 2007. There are few reports concerning the occurrence of bee diseases in Africanized honey bees (AHB) in Costa Rica. There are some preliminary studies, but the information is not entirely complete. For this reason, the aim of this study was to determine the prevalence of brood and adult bees diseases in AHB in Costa Rica. In our study, conducted between September and December 2007, 163 AHB colonies, belonging to 96 beekeepers from different geographic areas of Costa Rica, were randomly sampled. Most brood and adult bees samples were taken from colonies located in San Jose, Guanacaste and Alajuela. We found that $54.7 \%, 67.5 \%$ and $40.5 \%$ of the samples were positive to European Foulbrood, Nosema disease and Varroosis, respectively. A low prevalence of Tracheal mites (1.8\%) and Chalkbrood (4.4\%) were found. All samples were negative to American Foulbrood. The prevalence of European Foulbrood was greater in October, whereas in September we found the lowest incidence. Most of the samples positive to varroa

Programa de Patología Apícola, Centro de Investigaciones Apícolas Tropicales, Universidad Nacional, Heredia, Costa Rica. 
muestras positivas a varroa presentó un nivel de infestación leve, mientras que un 18,0\% reveló un nivel fuerte. Asimismo, un $11,9 \%$ de las muestras positivas a Nosema presentó un nivel de infección fuerte, principalmente en noviembre. La alta prevalencia de enfermedades, como Loque europeo y Nosemiasis, puede estar relacionada con la época del año en que se realizó el estudio y la escasa aplicación de medidas preventivas en los apiarios. Por lo anterior, es necesario implementar un programa sanitario, mediante muestreos periódicos, para conocer la situación sanitaria de las colmenas y asi poder brindar recomendaciones a los apicultores.

\section{INTRODUCCIÓN}

Uno de los principales problemas que afecta la apicultura mundial, esta relacionado con la sanidad de los apiarios. La presencia de enfermedades en las colmenas de abejas melíferas (Apis mellifera) reduce la producción de miel, y en ciertos casos pueden ocasionar la pérdida de la colonia, sino se controlan adecuadamente (Bailey y Ball 1991). En los últimos años, se ha reportado en España el despoblamiento y pérdida masiva de colmenas; a este fenómeno se le ha denominado Síndrome de Despoblamiento de la Colmena (SDC). En Estados Unidos se le conoce como Síndrome del Colapso de la Colonia (CCD, por las siglas en inglés) y más recientemente en Europa, lo reportan como pérdida de abejas. Una de las principales causas asociadas a este síndrome es la presencia de enfermedades infecciosas de origen viral y parasitario (Higes et al. 2006).

Al considerar el impacto de las enfermedades en la apicultura, se requieren métodos de diagnóstico de laboratorio eficientes para detectar de manera precisa los diferentes agentes patógenos (Shimanuki et al. 1992). Sin embargo, una de las mayores limitantes para la producción apícola a nivel nacional y regional, es la ausencia
$(60.0 \%, \mathrm{n}=61)$ showed a low mite infestation level, whereas $18.0 \%$ had a high level. November was the month with highest infection levels among cases of Nosema disease (11.9\% of the positive samples). These results are clear evidence of a high prevalence of European Foulbrood, Nosema disease and varroa mites in Africanized bees in Costa Rica. This prevalence could be related to the time of the year for the sampling period and the scant disease-prevention programs in the apiaries. For these reasons, it is necessary to implement a health program, by means of regular samplings of the apiaries, to know the sanitary situation of the colonies and provide relevant recommendations for beekeepers.

de prácticas de manejo que incluyan programas de diagnóstico, control y prevención de las enfermedades de la cría y de las abejas adultas (Calderón y Ortiz 2000).

Informes sobre la prevalencia y distribución de enfermedades de las abejas Africanizadas en Costa Rica, son aislados. Desde 1997, el laboratorio de Patología Apícola del Centro de Investigaciones Apícolas Tropicales (CINAT), ha analizado la incidencia de enfermedades de la cría y de las abejas adultas (en total se han analizado más de 5000 muestras). Las muestras procedieron de diferentes zonas del país y fueron enviadas por apicultores independientes, asociaciones de apicultores y empresas apícolas (Calderón y Ortiz 2000). Sin embargo, el envío de muestras no ha sido continuo ni metódico.

Para evaluar de manera sistemática la situación sanitaria de las colmenas del país, en el 2006 se realizó el primer muestreo nacional de enfermedades dirigido al análisis de abejas adultas, lo que permitió tener una mejor visión de lo que ocurre en la mayoría de apiarios del país (Calderón et al. 2007). No obstante, no se incluyó el diagnóstico de enfermedades de la cría (panales). Por lo anterior, el principal objetivo de este estudio fue determinar la prevalencia y distribución 
de las principales enfermedades que afectan tanto a la cría como a las abejas adultas en Costa Rica, mediante un muestreo sistemático y aleatorio de la mayoría de zonas apícolas del país.

El diagnóstico de laboratorio se hizo para determinar la presencia de Loque americano, Loque europeo, Varroosis, Cría de tiza, Polilla, Nosemiasis y Acariosis. A continuación se indican algunas de las principales características de estas enfermedades.

Loque americano: Es una enfermedad bacterial que afecta a la cría de las abejas melíferas. La principal característica es la putrefacción de la cría, asociada con un olor fétido, similar al pegamento (cola), lo cual ayuda preliminarmente para el diagnóstico de campo (Bailey y Ball 1991). Es causada por el Paenibacillus larvae, bacteria que forma esporas altamente resistentes, capaces de permanecer viables en el medio por varios años, lo que favorece la dispersión y alta patogenicidad (BID/OIRSA 1990, Calderón y Zamora 2007).

Loque europeo: Es causado por un conjunto de bacterias, entre las que destaca el Melissococcus plutonius, el cual se considera el agente que inicia la infección (Ritter 2001). Algunos de los síntomas que se observan en panales afectados por Loque europeo son cría salteada, que ha afectado la cría abierta, olor avinagrado y la costra que se forma al morir la cría se desprende fácilmente (Bailey y Ball 1991).

Varroosis: Es una parasitosis causada por el ácaro Varroa destructor, el cual afecta tanto a las abejas adultas como a la cría (Bew 1992). Se alimenta de la hemolinfa de la abeja, debilitándola y ocasionándole serios problemas, como alteraciones internas y la transmisión de agentes infecciosos, principalmente virus (Ball 1996, Dufol et al. 1991). Los síntomas que podrían observarse son reducción de la población de la colonia, opérculos perforados, las abejas se muestran inquietas, hay mortalidad de la cría, abejas con malformaciones en las alas, entre otros (Calderón et al. 1998, Van Veen et al. 1998).

Cría de tiza: Es una enfermedad fúngica causada por el hongo Ascosphaera apis, el cual afecta la cría de las abejas entre los 3 y 4 días de edad. Las esporas del hongo son ingeridas con el alimento larval y germinan en el tracto digestivo de la larva, formándose micelios que se expanden rápidamente, que recubren la superficie de la larva; la cría que muere se transforma en estructuras duras y de color blanco (momias), similares a un pedazo de tiza (Gilliam y Vandenberg 1997, Ritter 2001).

Polilla: La polilla de la cera, también conocida como palomilla o alevilla de la cera, es un pequeño insecto que pertenece al orden Lepidoptera, familia Pyralidae, los que se caracterizan por presentar un par de alas muy desarrollado y recubiertas con escamas. Se diferencian 2 tipos de polilla de la cera; la polilla de mayor tamaño corresponde a Galleria melonella (polilla mayor) y las más pequeña a Achroea grisella (polilla menor) (Bailey y Ball 1991). Las larvas de la polilla son auténticas minadoras, capaces de devorar diferentes materiales blandos, como los panales de cera (BID/OIRSA 1990).

Nosemiasis: Es causada por el microsporidio Nosema sp., el cual afecta el tracto digestivo de las abejas adultas (Bailey y Ball 1991). Hasta hace algunos años, se consideraba que la Nosemiasis en abejas melíferas, A. mellifera, era causada estrictamente por $N$. apis (Microspora, Nosematidae); mientras que la abeja asiática, $A$. cerana, era infectada básicamente por $N$. ceranae (Microspora, Nosematidae). Actualmente, se ha determinado la aparición de $N$. ceranae en abejas melíferas en países europeos, que causan daños cuantiosos, debido a su alta patogenicidad (Higes et al. 2006). Recientemente, se determinó la presencia de $N$. ceranae en Costa Rica, que afecta la mayoría de zonas apícolas del país (Calderón et al. 2008). Cuando se presentan algunos signos relacionados con Nosema, el problema es muy 
serio. Se observan abejas que no pueden volar, otras abejas con el abdomen distendido y en casos muy severos puede observarse disentería (diarrea) (Higes et al. 2006).

Acariosis: Es causada por el ácaro $A c a-$ rapis woodi, el cual es un parásito microscópico que afecta únicamente las abejas adultas, parasitando la parte pro-torácica de la tráquea (BID/OIRSA 1990). Ningún síntoma caracteriza exclusivamente esta enfermedad parasitaria; sin embargo la ausencia de signos no implica que la abeja este libre de Acariosis. Algunas manifestaciones que podrían estar relacionadas son abejas con alas distendidas, abanicándolas sin poder volar, abdomen distendido, abejas muertas o moribundas en frente de la colmena, entre otras (Bailey y Ball 1991, Ritter 2001).

\section{MATERIALES Y MÉTODOS}

Para determinar la prevalencia de Loque americano, Loque europeo, Cría de tiza, Polilla, Varroosis, Nosemiasis y Acariosis en Costa Rica, se realizó un muestreo de abejas adultas y panales con cría, de setiembre a noviembre del 2007. Las muestras de abejas y panales se colectaron de zonas apícolas como Los Santos, Acosta, Pérez Zeledón, Puriscal, Turrubares, Atenas, Orotina, Grecia, entre otras.

Número de colmenas muestreadas: Para determinar el número de colmenas que se muestrearon (tamaño de la muestra), se consideró la prevalencia de las enfermedades citadas anteriormente en 315 muestras analizadas en 2005-2006. Al tomar en cuenta la prevalencia esperada y el número de colmenas presentes en el país, se estimó que el número de colmenas a muestrear era de 160 a 200, con una confiabilidad del 90,0$95,0 \%$. Los apicultores y apiarios muestreados se seleccionaron de manera aleatoria; de la mayoría de apiarios se colectó una muestra de abejas y panal de una colmena, ubicada generalmente al inicio del apiario (corresponde con la entrada). En apiarios constituidos por más de 50 colmenas, se colectaron 2 muestras, mediante la selección de la colmena inicial y la intermedia.

\section{Características de la muestra}

Muestra de panal: De cada colmena se seleccionó un panal con cría (abierta y sellada) y se corto un pedazo de $10 \times 10 \mathrm{~cm}$. La muestra se envolvió en papel periódico y luego se colocó en un sobre de papel.

Muestra de abejas adultas: Se colectaron 100 abejas adultas de la cámara de cría (interior de la colmena), en un frasco plástico de boca ancha. Para la conservación de las muestras, a cada frasco se le adicionó alcohol al 70\%, de manera que las abejas quedaran cubiertas.

Además, a cada sobre de papel y a cada frasco se le indicó la siguiente información: 1-Nombre del propietario 2-Lugar de la colecta 3-Nombre del apiario 4-Número de la colmena 5-Fecha de la colecta 6-Número de colmenas en el apiario 7-Observaciones generales. En observaciones generales, se describió algún síntoma observado en la colmena.

Acreditación de técnicos apícolas: Para colectar las muestras a nivel de campo, se acreditaron 10 técnicos, los cuales se encargaron de tomar las muestras de los apiarios y su posterior envió al laboratorio. Además, los técnicos realizaron una encuesta al productor para obtener información sobre los tratamientos realizados durante el año.

Técnicas utilizadas en el laboratorio: Para realizar el diagnóstico de enfermedades, las muestras de panal y abejas se analizaron en el Laboratorio de Patología Apícola del Centro de Investigaciones Apícolas Tropicales (CINATUNA), ubicado en Lagunilla-Barreal de Heredia. A continuación se describen las técnicas utilizadas en el laboratorio para el diagnóstico de las enfermedades en los panales (cría) y abejas adultas. 


\section{Muestras de panal (cría)}

Loque americano y Loque europeo: Para el diagnóstico de Loque se utilizó la tinción de Gram, la gota colgante y el cultivo bacteriológico.

Tinción de Gram: Es una tinción diferencial empleada para la visualización de bacterias. Se utiliza tanto para referirse a la morfología celular bacteriana, como para realizar una primera aproximación a su diferenciación, considerándose bacterias Gram positivas las que se observan de color violeta y bacterias Gram negativas las que se visualizan de color rojo. Para aplicar esta tinción, se preparó un frotis con la cría afectada, el cual se fijo con calor y se tiño inicialmente con cristal violeta. Posteriormente, el frotis se lavo con agua y se cubrió con una solución yodada. Luego se decoloró con una mezcla de alcohol etílico/acetona y finalmente se cubrió con safranina (color de contraste). El examen de la lámina se realizó en el microscopio con el objetivo de inmersión (100x) (Bailey y Ball 1991).

Técnica de la gota colgante: La cría afectada se mezcló con una gota de agua destilada en un cubreobjetos, hasta que se formó una película opaca, la cual se fijó al cubreobjetos con calor. Se procedió a teñir el frotis con fuchsina-fénica durante 5-7 s. Finalmente, se colocó el cubreobjetos sobre un portaobjetos con aceite de inmersión. Para el examen de la lámina, se utilizó el objetivo de inmersión del microscopio, mediante el cual se ubicó el área donde el agua se estancó entre los grumos de aceite, para determinar la presencia de esporas flotantes. Únicamente las esporas del P. larvae (agente causal del Loque americano) muestran movimiento Browniano, mientras que las esporas de otros agentes se observan fijas al cubreobjetos (Ritter 2001).

Cultivo bacteriológico: Para el cultivo bacteriológico se utilizó el medio Infusión Cerebro-Corazón enriquecido con $0,1 \mathrm{mg}$ de Hidroclorato de tiamina (vit B1). Se incubó por un periodo de $96 \mathrm{~h}$ a $37^{\circ} \mathrm{C}$ en una atmósfera de $5-10 \%$ de $\mathrm{CO}_{2}$ (Bailey y Ball 1991). Asimismo, se uso el medio de cultivo J, el cual contiene triptona, extracto de levadura, K2HPO4, agar y glucosa. Es importante indicar que este medio propicia un mejor crecimiento de la bacteria $P$. larvae y favorece su esporulación. Al igual que el medio de cultivo anterior, el medio $\mathrm{J}$ se incubó por $96 \mathrm{~h}$ a $37^{\circ} \mathrm{C}$ en una atmósfera de 5-10\% de $\mathrm{CO}_{2}$ (BID/OIRSA 1990).

Varroosis: Para determinar el nivel de infestación de los panales, se realizó un examen directo de 50 celdas de obrera selladas. Se desoperculó cada celda y se revisó la cría (pupa) minuciosamente, así como el interior de la celda. Inicialmente se observó a simple vista y posteriormente por medio de una lupa. El nivel de infestación fue expresado como un porcentaje, el cual se obtuvo mediante la relación del número de celdas con ácaros, entre el total de celdas examinadas x 100 (Ritter 2001).

Cría de tiza: Para esta enfermedad causada por hongos, se uso la técnica del examen directo y el cultivo. Larvas afectadas por esta enfermedad aparecen como estructuras duras y de color blanco, que pueden tornarse gris o negro, según la formación de los cuerpos fructíferos. Las muestras de cría que presentaban los síntomas indicados, se revisaron preliminarmente mediante el examen directo. Cada larva fue montada en $\mathrm{KOH}$ al $5 \%$ y revisada al microscopio a 40 y 100x. Posteriormente, algunas de ellas se cultivaron en el medio Czapec Dox y se incubaron a temperatura ambiente (Gilliam y Vandenberg 1997).

Polilla: La presencia de polillas adultas, larvas en distinto estado de desarrollo, ninfas, defecaciones, panales destruidos, entre otros, son síntomas que se consideraron en los panales para el diagnóstico de esta plaga (Bailey y Ball 1991). El diagnóstico diferencial entre ambos tipos de polilla, que considera el tamaño de los adultos, no se realizó en este estudio.

\section{Muestras de abejas adultas}

Nosemiasis: Para el diagnóstico de este microsporidio se aplicó el método de Cantwell. Se colocaron 15 abejas sobre un papel absorbente. 
Posteriormente, los abdómenes fueron separados y colocados en un mortero, donde fueron macerados, con 1,0 ml de agua destilada total $=15,0 \mathrm{ml}$ por cada abdomen. El macerado se homogenizó, agitándolo constantemente durante un min, luego una gota de la suspensión fue colocada en un portaobjetos. El frotis se examinó en el microscopio a un aumento de 40x y las esporas fueron identificadas por ser ovaladas, brillantes y refringentes. El nivel de infección se reportó con el promedio de esporas observadas por campo de visión del microscopio y se indicó como leve, moderado o fuerte (Cuadro 1) (Cantwell 1970).

Cuadro 1. Nivel de infección de Nosemiasis mediante el método de Cantwell.

\begin{tabular}{cc}
\hline Nivel infección & Cantidad de esporas por campo \\
\hline Leve & $1-10$ \\
Moderado & $11-20$ \\
Fuerte & 21 o más \\
\hline
\end{tabular}

Acariosis: Se realizó un examen directo de 15 abejas con la técnica del disco mesotorácico. A cada abeja se le realizó un corte transversal (a manera de disco) de la parte anterior del tórax (contiene las tráqueas). Los discos se colocaron en Hidróxido de Potasio $(\mathrm{KOH})$ al 5\% y se incubaron a $37^{\circ} \mathrm{C}$ por $24 \mathrm{~h}$. Las tráqueas se examinaron preliminarmente en el estereoscopio y aquellas sospechosas de Acariosis (levemente oscuras=melanización) se revisaron al microscopio a 10 y 40x (Shimanuki et al. 1992).

Varroosis: Para el diagnóstico del ácaro varroa en abejas adultas se utilizó el método de tamizaje. Se colocó una muestra de aproximadamente 50 abejas en un frasco de boca ancha. Se agregó al frasco una solución jabonosa (300 $\mathrm{ml}$ de agua más $0,5 \mathrm{~g}$ de detergente en polvo), la cual se agitó por 1 min para separar los ácaros del cuerpo de las abejas. El líquido se filtró a través de un cedazo de 8 agujeros por pulgada para separar las abejas. Luego, el líquido filtrado se tamizó por segunda vez a través de un cedazo fino, donde quedaron retenidos los ácaros. Se cuantificaron tanto los ácaros como las abejas, con un reporte de infestación de la muestra, obtenido de la relación porcentual del: número de ácaros/número de abejas adultas x 100 (Bailey y Ball 1991).

\section{RESULTADOS Y DISCUSIÓN}

Se analizaron un total de 161 muestras de panal con cría y 163 muestras de abejas adultas, pertenecientes a 96 apicultores. La mayoría de muestras correspondió a las provincias de San José, Guanacaste y Alajuela (Cuadro 2). No se tomaron muestras de Heredia ni de Limón, debido a que la apicultura en estas zonas es escasa (principalmente por las condiciones climáticas).

De las muestras de panal analizadas, un alto porcentaje resulto positiva a Loque europeo y Varroosis; mientras que todas las muestras resultaron negativas a Loque americano (Cuadro 3).

Cuadro 2. Muestras de panal $(n=161)$ y abejas adultas $(n=163)$ analizadas por provincia para el diagnóstico de enfermedades en Costa Rica (setiembre-noviembre del 2007).

\begin{tabular}{ccccc}
\hline \multirow{2}{*}{ Provincia } & \multicolumn{2}{c}{ Panales con cría } & \multicolumn{2}{c}{ Abejas adultas } \\
& Número de muestras & $\%$ & Número de muestras & 32,5 \\
\hline San José & 56 & 34,8 & 41 & 25,2 \\
Guanacaste & 51 & 3,7 & 35 & 21,5 \\
Alajuela & 29 & 18,0 & 32 & 19,6 \\
Puntarenas & 23 & 14,3 & 2 & 1,2 \\
Cartago & 2 & 1,2 & & \\
\hline
\end{tabular}


Cuadro 3. Muestras de panales examinadas para el diagnóstico de Loque americano, Loque europeo, Varroosis, Cría de tiza y Polilla.

\begin{tabular}{cccc}
\hline Enfermedad & Muestras analizadas & Muestras positivas & $(\%)$ \\
\hline Loque americano & 161 & 0 & 0 \\
Loque europeo & 161 & 88 & 54,7 \\
Varroosis & 161 & 61 & 37,9 \\
Cría de tiza & 161 & 7 & 4,4 \\
Polilla & 161 & 53 & 32,9 \\
\hline
\end{tabular}

Loque americano: El primer reporte oficial de Loque americano en Costa Rica indica la presencia de esta enfermedad bacterial desde 1985 (Blanco 1990). En el presente estudio todas las muestras de panal analizadas resultaron negativas a Loque americano. Lo anterior corresponde con lo observado en los últimos 12 años, en los reportes de esta enfermedad bacterial han sido escasos. Al respecto, en mayo de 1999, se determinó la presencia de Loque americano, en muestras de panal provenientes de San Ignacio de Acosta. Asimismo, en diciembre del 2006, un apiario ubicado en el cantón de Mora (Ciudad Colón), fue inspeccionado debido a la sospecha de cría enferma. Se revisaron 10 colmenas, de las cuales 2 presentaron serios problemas de mortalidad en la cría sellada. Con base en la inspección sanitaria realizada al apiario afectado, la sintomatología clínica observada en la cría sellada y en los diferentes análisis de laboratorio, se determinó la presencia de P. larvae, agente causal de Loque americano (Calderón y Zamora 2007). Tanto el caso de Acosta, como el del cantón de Mora, se confirmaron en el Laboratorio de Patología Apícola del CINAT. Debido a la importancia de esta enfermedad bacterial y acorde con lo reportado en la literatura (Bailey y Ball 1991, Ritter 2001), se recomendó la eliminación de las colmenas más afectadas y el tratamiento de las restantes. Asimismo, se restringió la movilización de colmenas del área afectada. Al tomar en cuenta la facilidad de transmisión de la enfermedad, la práctica intensiva de trasladar colonias de abejas a diferentes zonas apícolas, la dispersión de enjambres africanizados y la ausencia de prácticas adecuadas de control, se determina que la incidencia de esta enfermedad hubiera tenido efectos muy drásticos.

Loque europeo: Un 54,7 de las muestras analizadas resultaron positivas a Loque europeo (Cuadro 3). En años recientes, se ha observado un aumento en la presencia de esta enfermedad en Costa Rica, lo cual corresponde con lo determinado en este estudio (Calderón y Ortiz 2000). La mayor prevalencia correspondió a octubre; mientras que en setiembre se determinó la menor cantidad de muestras positivas (Figura 1). La provincia con mayor prevalencia fue San José, mientras que en Puntarenas se determinó la menor cantidad. Algunos de los cantones que resultaron más afectados por Loque europeo fueron Hojancha, Coto Brus, Acosta, San Ramón, entre otros.

El alto índice de prevalencia de Loque europeo puede estar relacionado con la época del año en que se realizó el estudio (setiembrenoviembre). Las condiciones de alta humedad presentes en la época lluviosa y la reducción en la población de abejas en la colmena (colmenas débiles debido a la escasez de alimento), favorecen el desarrollo de esta enfermedad bacterial (Bailey y Ball 1991). Se ha reportado que en casos de infección leve, el Loque europeo puede ser controlado por abejas que presentan un alto comportamiento higiénico (remoción de la cría afectada) (Shimanuki et al. 1992). Sin embargo, en colmenas débiles puede persistir, lo que ocasiona una disminución significativa en la producción de miel y un retraso en el desarrollo de la población de abejas pecoreadoras (abejas 


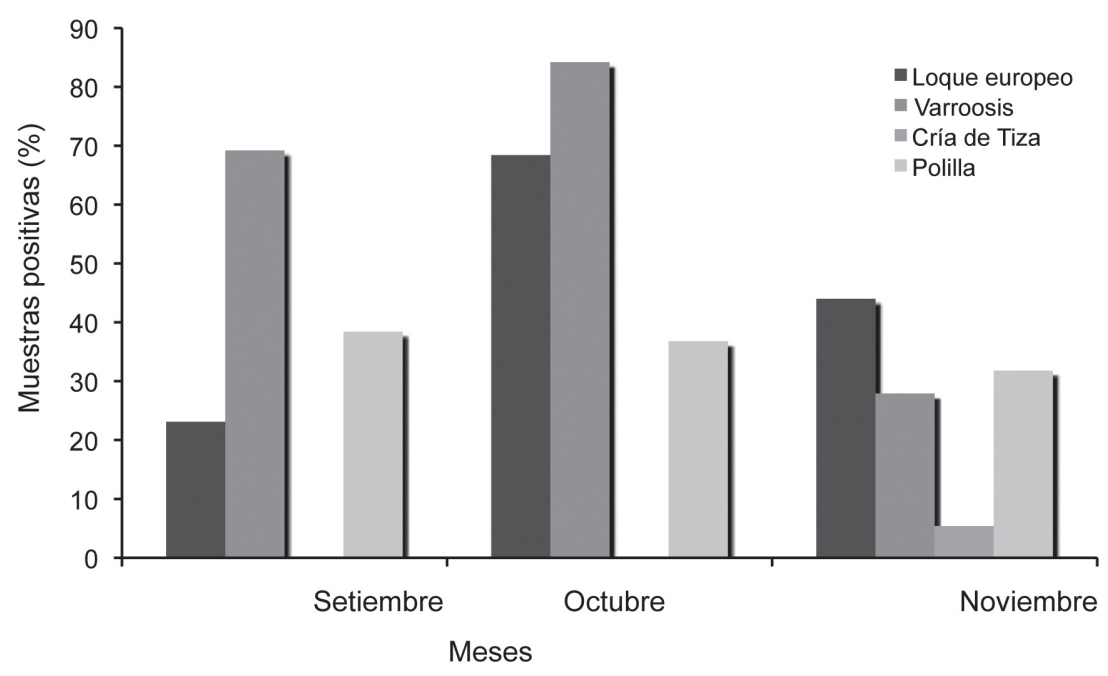

Fig.1. Prevalencia de enfermedades que afectan la cría de las abejas melíferas.

que colectan polen y néctar), que comprometería la viabilidad de la colonia.

Varroosis: La Varroosis es considerada como uno de los problemas sanitarios de mayor importancia económica a nivel mundial (Ritter 2001). En nuestro país apicultores de diferentes zonas apícolas han reportado la pérdida de colmenas y una reducción en la producción de miel, debido a la presencia del ácaro $V$. destructor en los apiarios (Calderón et al. 1999).

En este estudio un 37,9\% de las muestras de panal resultaron positivas a Varroosis. Mientras que en las muestras de abejas adultas, un $40,5 \%$ resultaron positivas, lo cual es similar a lo observado en el 2006, en que se determinó un 42,0\% de muestras con presencia del ácaro $V$. destructor (Calderón et al. 2007).

Un aspecto a resaltar es que el $60,7 \%$ $(\mathrm{n}=61)$ de las muestras de panal positivas presentó un nivel de infestación leve, similar al encontrado en abejas adultas el cual corresponde a un $60,6 \%$ $(\mathrm{n}=66)$. Mientras que un $18,1 \%$ y un $16,7 \%$ de las muestras presentaron un nivel de infestación fuerte en panales y abejas adultas, respectivamente.

En octubre se determinó el mayor número de muestras de panal positivas a varroa $(84,2 \%$ $\mathrm{n}=61$ ); mientras que en noviembre se observó la menor cantidad $(27,9 \% \mathrm{n}=61)$. El nivel de infestación observado en noviembre, puede estar relacionado con la aplicación de productos acaricidas para su control. Se debe tomar en cuenta que el daño que la Varroosis causa a las colmenas depende del grado de infestación. Se estima que el mayor efecto negativo sobre la producción se observa cuando la población de ácaros supera el 10\% de infestación (Ritter 2001). La provincia con la mayor prevalencia a varroa correspondió a Puntarenas, mientras que la menor prevalencia se observó en Guanacaste (Figura 1). Aunque Cartago presentó una prevalencia del $100 \%$, únicamente se evaluaron 2 muestras por lo que dicho resultado no se considera representativo. En diciembre del 2008, se determinó una alta infestación de varroa (nivel infestación fuerte=superior al 13,0\%) en colmenas ubicadas en Jicaral de Puntarenas y en Linda Vista de Cartago, aspecto importante de resaltar ya que en diciembre inicia la cosecha de miel en Costa Rica. Para esta época, las colmenas deberían presentar bajos niveles de infestación de varroa y estar en buenas condiciones sanitarias para el inicio de la producción de miel. 
Cría de tiza: En el 2004 se reportó la presencia del hongo A. apis, agente causal de la Cría de tiza en colmenas de abejas Africanizadas en Costa Rica (Calderón et al. 2004). Desde entonces, se ha observado con cierta frecuencia la presencia de este hongo en muestras de panal remitidas al laboratorio. En el presente estudio se determinó una baja prevalencia de cría de tiza, donde noviembre es el mes con mayor cantidad de muestras positivas (Figura 1). La provincia con la mayor prevalencia correspondió a San José, mientras que la menor se observó en Guanacaste. En la mayoría de panales con cría de tiza, se determinó la presencia de otras enfermedades como Loque europeo y Varroosis. Se indica que la presencia de esta enfermedad fúngica esta relacionada con una baja población de abejas adultas (colmenas débiles: incapaces de mantener la temperatura de la cámara de cría constante), y a condiciones de alta humedad relativa (estación lluviosa) (Bailey y Ball 1991). De manera general, la cría de tiza no es considerado un problema muy serio para la apicultura, reportándose en muchos casos como una condición de escasa importancia económica (Ritter 2001).
Polilla: Un 32,9\% de las muestras analizadas resultaron positivas a polilla, presentándose la mayor prevalencia en setiembre (Figura 1). La provincia con mayor cantidad de muestras positivas fue San José, mientras que Guanacaste presentó el menor número de panales positivos a polilla. Los cantones más afectados son: Acosta, Aserrí, Hojancha y Jicaral. Se ha indicado que ciertas condiciones favorecen el desarrollo de la polilla. Por ejemplo, la polilla mayor, G. melonella, produce daño en colonias débiles, especialmente en aquellas colmenas que reciben una mala alimentación durante la época de escasez o en colmenas altamente infestadas con el ácaro $V$. destructor (Shimanuki et al. 1992). Asimismo, la polilla afecta colmenas abandonadas por las abejas (evasión) o panales que el apicultor deja tirados en el apiario. Una colonia con una población moderada de abejas no permite el desarrollo de la polilla, ya que al emerger las larvas del lepidóptero, son eliminadas de la colmena por las obreras (BID/OIRSA 1990, Ritter 2001).

Un número considerable de muestras de abejas adultas examinadas resultaron positivas a Nosemiasis (Figura 2); mientras que la mayoría fueron negativas a Acariosis (Cuadro 4). La alta

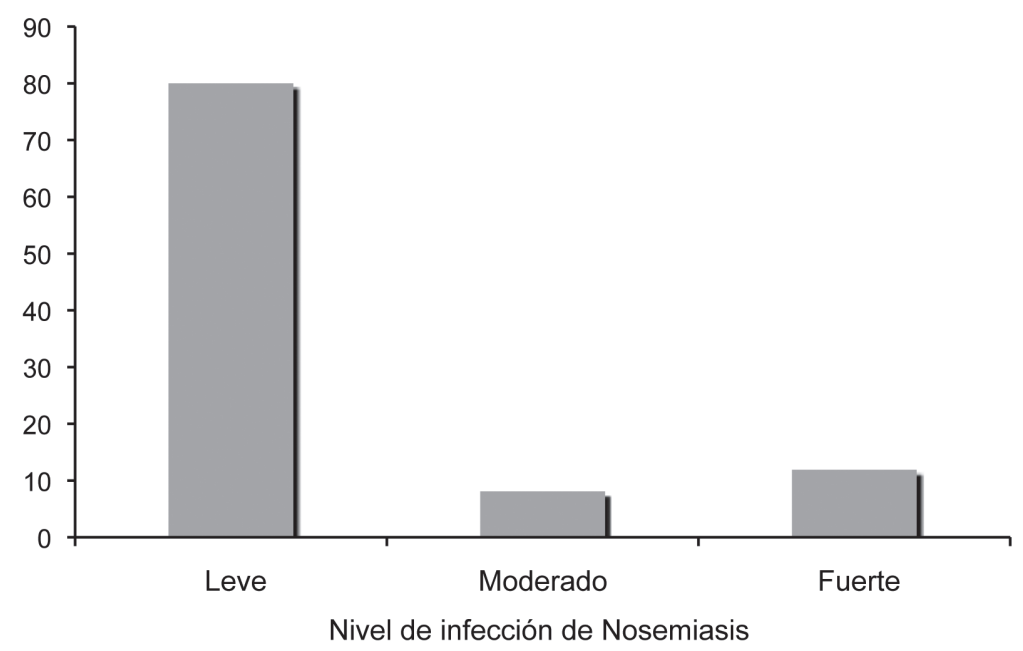

Fig. 2. Nivel de infección de Nosemiasis en abejas melíferas $(n=110)$. La mayoría de muestras presentó un nivel de infección leve. 
Cuadro 4. Muestras de abejas adultas analizadas para el diagnóstico de Nosemiasis, Acariosis y Varroosis en Costa Rica $(n=163)$ (setiembrenoviembre del 2007).

\begin{tabular}{ccc}
\hline Enfermedad & $\begin{array}{c}\text { Muestras } \\
\text { positivas }\end{array}$ & $(\%)$ \\
\hline Nosemiasis & 110 & 67,5 \\
Acariosis & 3 & 1,8 \\
Varroosis & 66 & 40,5 \\
\hline
\end{tabular}

prevalencia de Nosemiasis y la poca incidencia de Acariosis; coincide con los resultados obtenidos en el primer muestreo nacional realizado en el 2006, en el cual se observó una cantidad considerable de muestras positivas a Nosema, y una prevalencia inferior al 1,2\% para Acariosis (Figura 3) (Calderón et al. 2007).

Nosemiasis: La prevalencia de Nosemiasis obtenida en el presente estudio (67,5\%), es considerablemente mayor a la observada en el 2006 (28,0\% de muestras positivas) (Figura 3) (Calderón et al. 2007, Calderón y Fallas 2009).

La mayor presencia de Nosema se determinó en la provincia de Alajuela, principalmente en los cantones de San Mateo y San Ramón; mientras que en Guanacaste y San José se observó la menor prevalencia (Figura 4). La mayoría de muestras positivas a Nosemiasis $(n=110)$ presentó un nivel de infección leve (Figura 2). Se debe indicar que en colmenas con baja cantidad de esporas, la Nosemiasis no se manifiesta clínicamente, ya que se encuentra en un estado de latencia. Sin embargo, ciertas condiciones como periodos de encierro de las abejas dentro de la colmena (hacinamiento), debido principalmente a lluvias prolongadas, fríos intensos o fuertes vientos favorecen su desarrollo, lo que ocasiona que un nivel de infección leve, aumente a moderado o incluso alcance un nivel fuerte (Ritter 2001). Un 11,9\% de las muestras analizadas presentó un nivel de infección fuerte, principalmente en noviembre, mes en el que las colmenas deben estar en buenas condiciones sanitarias para el inicio de la cosecha de miel.

Acariosis: El 1,8\% de muestras positivas a Acariosis determinado en este estudio (Cuadro 4), es similar a lo observado en el 2006, donde se obtuvo una prevalencia del $1,1 \%$ (Figura 3 ). Lo anterior, corresponde con la disminución en la prevalencia de esta enfermedad parasitaria observada en los últimos años en Costa Rica. En 1999, un 15,0\% ( $n=112)$ de las muestras analizadas resultó positiva a Acariosis, con niveles de

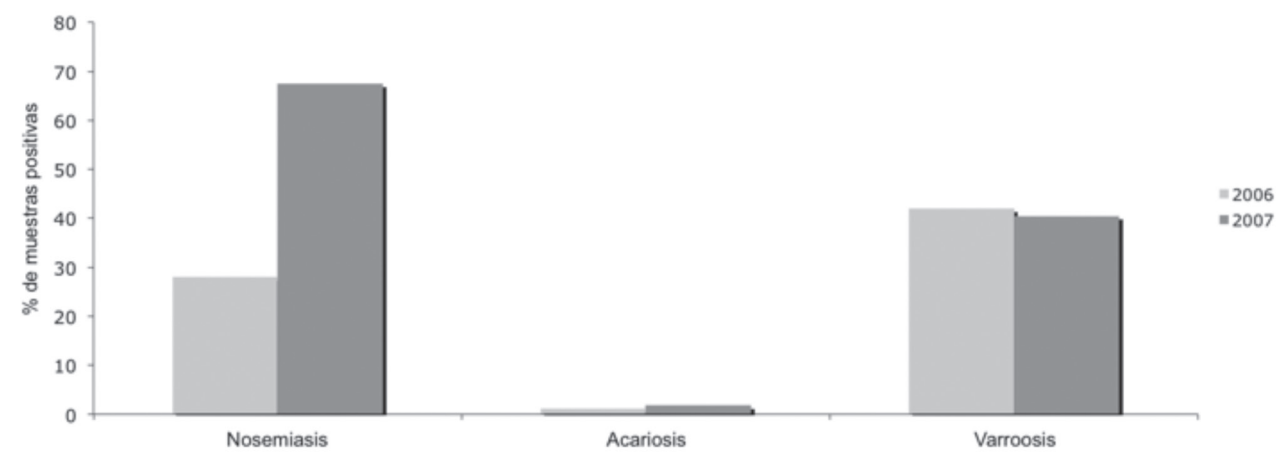

Fig. 3. Prevalencia de Nosemiasis, Acariosis y Varroosis determinada en Costa Rica en el $2006(n=262)$ y $2007(n=163)$. 


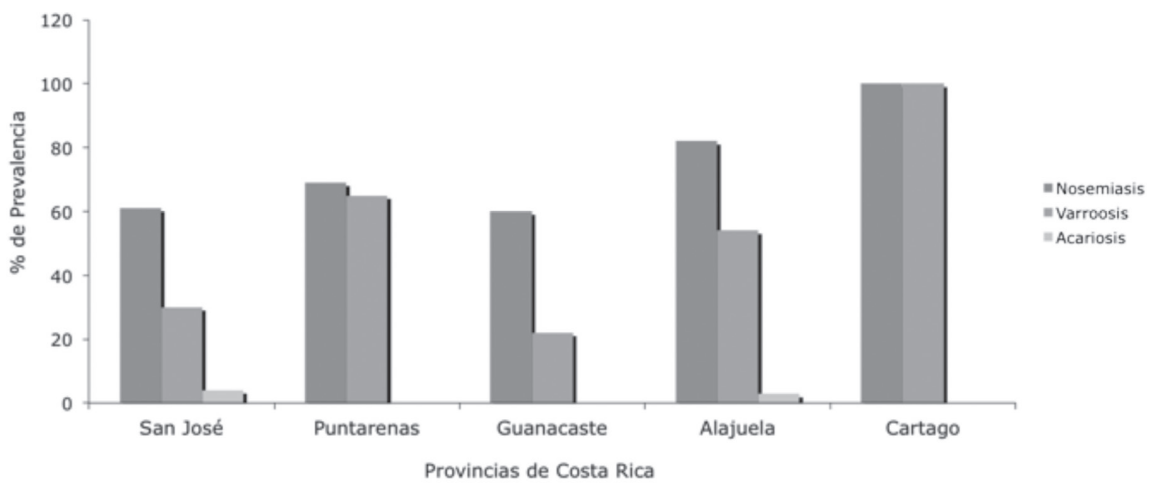

Fig. 4. Incidencia de Nosemiasis, Varroosis y Acariosis en abejas Africanizadas procedentes de diferentes provincias de Costa Rica.

infección de moderado a fuerte (Calderón y Ortiz 2000). La aplicación intensiva de ácido fórmico al $65-85 \%(\mathrm{v} / \mathrm{v})$ para el control del ácaro $V$. destructor en nuestro país (1997-2002), podría estar relacionada con este descenso, ya que este ácido posee una alta efectividad en el control del ácaro A. woodi (Calderón et al. 2009, Ritter 2001).

La alta incidencia de ciertas enfermedades, como Loque europeo, Varroosis y Nosemiasis determinada en este estudio, puede estar relacionada con la época del año en que se realizó la investigación (estación lluviosa) y la escasa aplicación de medidas preventivas en los apiarios. Es frecuente observar colmenas con panales oscuros, exceso de marcos vacíos y baja población de abejas adultas. Asimismo, la mayoría de apicultores del país no realiza diagnóstico preventivo de enfermedades y en algunos casos, se exceden en la aplicación innecesaria e inadecuada de medicamentos (antibióticos, acaricidas). Por lo anterior, es necesario implementar un programa sanitario en los apiarios mediante muestreos periódicos (2 veces al año), para conocer la situación sanitaria de las colmenas. Esto permitirá tomar acciones inmediatas relacionadas con la prevención y la aplicación de medidas oportunas para el control de las enfermedades. Principalmente durante la estación lluviosa, época en la que hemos determinado con base en el estudio realizado, una alta incidencia de enfermedades.

\section{AGRADECIMIENTOS}

Deseamos agradecer a los apicultores que participaron en este muestreo nacional de enfermedades. A los diferentes técnicos del Ministerio de Agricultura y Ganadería (MAG), especialmente a la Lic. Ana Cubero, por su participación activa en la colecta y envió de muestras. Asimismo, agradecemos a los asistentes que participaron en el procesamiento de las muestras en el laboratorio.

\section{LITERATURA CITADA}

BAILEY L., BALL B. 1991. Honey Bee Pathology. Second Edition. Academic Press, London, UK. 193 p.

BALL B. 1996. Honey bee viruses: a cause for concern. Bee World 77:117-119.

BEW M. 1992. Varroasis disease of honey bees-diagnosis and control. MAFF leaflet, London, UK. 8 p.

BID/OIRSA. 1990. Enfermedades de la cría y de las abejas adultas, pp. 147. In: Programa regional para el manejo y control de la abeja africanizada (ed). Enfermedades y Plagas de la Abeja Melífera Occidental, San Salvador, El Salvador.

BLANCO G. 1990. Loque americana en las abejas melíferas de Costa Rica. Ciencias Veterinarias 12:2-3. 
CALDERÓN R.A., ARCE H., VAN VEEN J. 1998. Detección, distribución y control de Varroa jacobsoni Oudemans en Costa Rica. Ciencias Veterinarias 21:29-38.

CALDERÓN R.A., ARCE H., VAN VEEN J., LALAMA K. 1999. Efectividad de algunos productos utilizados para el control de la Varroasis en Costa Rica, pp. 24-26. In memorias del VI Congreso Nacional de Apicultura.

CALDERÓN R.A., FALLAS N. 2009. Prevalencia del microsporidio Nosema sp., en abejas Africanizadas en Costa Rica. Boletín de Parasitología 10:1-4.

CALDERÓN R.A., ORTIZ A. 2000. Principales enfermedades que afectan a las abejas melíferas. Notas Apícolas Costarricenses 6:1-24.

CALDERÓN R.A., RIVERA G., SÁNCHEZL.A.,ZAMORA L.G. 2004. Chalkbrood (Ascosphaera apis) and some other fungi associated with Africanized honey bees (Apis mellifera) in Costa Rica. Journal of Apicultural Research 43:187-188.

CALDERÓN R.A., SÁNCHEZ L., FALLAS N. 2009. Presencia de Acariosis en abejas melíferas en Costa Rica. Boletín de Parasitología 10:1-4.

CALDERÓN R.A., SÁNCHEZ L., FALLAS N., CUBERO A., MUÑOZ A. 2007. Prevalencia de las principales enfermedades que afectan a las abejas melíferas en Costa Rica, pp. 87. In: Memorias del IX Congreso Nacional de Apicultura.

CALDERÓN R.A., SÁNCHEZ L.A., YAÑEZ O., FALLAS N. 2008. Presence of Nosema ceranae in Africanized honey bee colonies in Costa Rica. Journal of Apicultural Research and Bee World 47:328-329.

CALDERÓN R.A.,ZAMORA L.G. 2007. Presencia de Loque americana en colmenas de abejas africanizadas en Costa Rica, pp. 87. In: Memorias del IX Congreso Nacional de Apicultura.

CANTWELL G.E. 1970. Standard methods for counting nosema spores. American Bee Journal 110:222-223.

DUFOL M., MARTÍNEZ A., SÁNCHEZ C. 1991 Comparative test of fluvalinate and flumethrin to control Varroa jacobsoni Oudemans. Journal of Apicultural Research 30:103-106.

GILLIAM M., VANDENBERG J. 1997. Fungi, pp. 718. In: R.A. Morse y R. Nowogroddzki (eds) Honey bee Pest, Predators and diseases. Cornell University Press, Ithaca, NY, USA.

HIGES M., MARTIN R., MEANA A. 2006. Nosema ceranae, a new microsporidian parasite in honey bees in Europe. Journal of Invertebrate Pathology 92:93-95.

RITTER W. 2001. Enfermedades de las abejas. Editorial Acribia S.A., Zaragoza, España. 146 p.

SHIMANUKI H., KNOX D., DE JONG D. 1992. Diseases of pests of honey bees, pp. 1324. In: J.M. Grahan (ed). The Hive and the Honey Bee. Dadant and sons, Illinois, USA.

VAN VEEN J.W., CALDERÓN R.A., CUBERO A., ARCE H.G. 1998. Varroa jacobsoni Oudemans in Costa Rica: Detection, spread and treatment with Formic Acid. Bee World 79:5-10. 